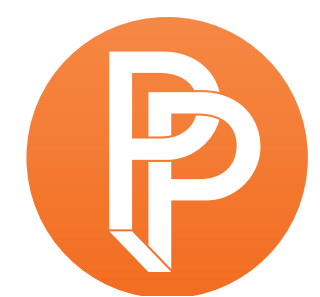

PERFORMANCE

PHILOSOPHY

\title{
WORK(S) AND (NON)PRODUCTION IN CONTEMPORARY MOVEMENT PRACTICES
}

\author{
HETTY BLADES COVENTRY UNIVERSITY
}

Introduction

This paper considers how the presentation of movement practices in performance contexts blurs the distinction between making and performance, raising questions about the nature of dance 'works'. I examine the way that practice is presented by UK dance artists Katye Coe and Charlie Morrissey and American choreographer Deborah Hay, and how this troubles distinctions between 'internal' practices and 'external' performance. In response to this, I examine the applicability of the 'work-concept' (Goehr 1992) within such contexts.

As Laura Cull Ó Maoilearca and Alice Lagaay suggest in their introduction to the inaugural volume of the Performance Philosophy book series $(2014,4)$, current work in this emergent field tends to respond primarily to Continental philosophical perspectives. Whilst the geographical distinctions associated with the Continental and analytic schools no longer strictly apply, there appears to be a general distinction maintained, perhaps due to differences in methods, language and lineage. ${ }^{1}$ There are multiple possible reasons for the leaning toward Continental perspectives within Performance Philosophy, including scepticism towards analytic methodologies. For example, writing in this journal in 2015, Bojana Cvejić refers to the 'positivist logic' $(2015,10)$ of some analytic writing. Positivist thinking is often associated with scientific enquiry, and sees the world as made up of truths, which can be (dis)proved through 'objective' testing. Within a field dedicated to a conception of performance and philosophy as confluent (Cull Ó Maoilearca 2014, 15), this approach would be problematic, as theorising arises from the lived experience of performance 
making and spectatorship, allowing for subjectivities to be foregrounded and multiple versions of reality to be acknowledged. However, here I hope to demonstrate how the work of some analytic philosophers challenges charges of positivism, offering philosophical suggestions that arise from social and historical practices (Goehr 1992; Davies 2004, 2009; Thomasson 2005, 2006). Bringing these perspectives into dialogue with Performance Philosophy, and therefore Continental viewpoints, I show the relevance of some writing in this field for advancing our thinking about dance and performance. ${ }^{2}$

Cvejić suggests that 'the incapacity of Western philosophy and aesthetics to think dance might have to do with the tradition of applying to it the common regime of "the work of art" (oeuvre)' (Cvejić $2015,10)$. Indeed, the notion of the 'work', and the connotations of a stable, sellable entity, has political implications, and is rebuffed by some practitioners (Pakes 2015). However, I argue that the 'work-concept' (which I will discuss in more detail shortly) remains in use in dance practices; but that the term is frequently used to refer to practice, process and product interchangeably, suggesting that the work of dance exists as a confluence of labour, knowledge and performance. Furthermore, I argue that in some cases, the distinction between the work of making and the work of art cannot be maintained. This observation implies that the 'work' is not a stable object, distinct from its creation, but an, arguably more complex entity, which is a confluence of both process and product.

Cvejić critiques in particular those analytic philosophical perspectives that maintain a duality between the work and performance event $(2015,10)$. The ontology of dance works has been addressed by many analytic philosophers and dance scholars. ${ }^{3}$ Although there is not always agreement, many find it useful to apply the type-token schema, first introduced by linguist Charles Pierce (1906) and developed for art by Joseph Margolis (1959) and Richard Wollheim (1980). Under this schema, a 'work' is an abstract type, of which each performance is a token, offering a way of thinking about works as real and stable (albeit abstract) entities. Responding to Frédéric Pouillaude's work on the ontology of dance, ${ }^{4}$ Cvejić suggests that

\footnotetext{
Pouillaude has reformulated the type-token duality in a framework more suited to dance: the work of dance exists at once as a 'public object', shared and offered for judgment, and as a 'resistant object', capable of surviving the death of its initial protagonists, or in other words, existing beyond the experience or memory of its creation and performance processes. (Cvejić 2015, 10)
}

Although Pouillaude's view does not directly challenge the type-token schema, it appears to foreground the coexistence of the 'public' object (the performance) and a 'resistant' one (the work), perhaps troubling the perceived duality discussed by Cvejić $(2015,10)$. However, a distinction appears to be maintained between the 'object' (as both public and resistant), and 'the experience or memory of its creation and performance processes'.

This view does not appear particularly contentious, and works tend to continue to exist beyond the death of the person or people who made them-meaning that a distinction can arguably be drawn between the process of making the work and the object itself. Indeed, the separation of the public 
art object or event from the process of making has been generally maintained in the history of philosophical writing about dance. Writing in the 1970s, for example, Adina Armelagos and Mary Sirridge point to the tradition of distinguishing between art-making processes and objects (1978, 129). In her writing from the 1990s, dance theorist Laurence Louppe describes dance 'objects' as visible to, and interpretable by, a public ([1997] 2010, 202). She suggests that in the site of performance, 'the dancer's thought and work cease to be creation activities and become (powerful) tools of actualisation' ([1997] 2010, 203). And in more recent writing, Cvejić maintains a distinction between the public performance and private, or internal, aspects of the practice or process. She suggests that considering the ontological status of dance works 'entails paying attention to the idiosyncratic relationship between the sharable (exterior or public) and the reticent, self-absorbed or shattered aspects of a dance work' $(2015,10)$.

On the one hand, this distinction seems logical, as making processes are often focussed towards the development of an external event. Even when aspects of the process are made public, they tend to be considered distinct from the performance. However, on the other hand some dance practices muddle this distinction, such as cases in which artists share their 'internal' practice in performative contexts. These are the kinds of practices that I will focus on in this article. For example, in the collaborative work of Coe and Morrissey, the areas of practice and performance are enmeshed to the point that the distinction between the 'sharable' and 'reticent' (Cvejić 2015, 10) seems not to apply. ${ }^{5}$ argue that this points to a conflation of the work-verb (used to refer to the labour of dance practice) with the work-noun, troubling the distinction between the process and performance of (a) dance work.

In analysing their practice, I consider how the 'work-concept' operates in dance contexts, drawing on the use of this term by philosopher of music Lydia Goehr (1992). Although writing in the tradition of analytic philosophy, Goehr critiques certain features of the school, drawing a distinction between analytic and historical modes of philosophical investigation (4). She suggests that in matters of ontology the analytic paradigm is concerned with finding the best description of what a work is, whereas the second approach considers the way the concept of the work emerged and functions (4). Goehr undertakes what she refers to as a 'major methodological transition' (90) by moving away from asking what kind of object a musical work is, to asking what kind of concept the work-concept is. Following this line of thought, I suggest that the form and function of the workconcept as it pertains to dance can be explored through consideration of those who use the term, in what contexts and to what purposes. Although the concept of the work can arguably be deployed without the use of the term, considering the way that (a) dance work is discussed reveals how the concept is understood and articulated in practice.

The importance of context is emphasised by various analytic philosophers. For example, Amie Thomasson argues that matters of artwork ontology must be considered in relation to social practices $(2005,4-8)$. Although adopting a slightly different stance, David Davies $(2009,159)$ also argues that ontological claims should be methodologically constrained by common practices. This call for the centrality of human experiences in ontological methodology is similarly articulated by Julie Van Camp (2006). Although these philosophers are not necessarily aligned with the pragmatist 
tradition in philosophy, in various ways they do call for a 'pragmatic approach' (Van Camp 2006, 43). So, following this methodology, we might ask how the term and concept of the 'dance work' functions in the dance world? ${ }^{6}$

Acknowledging the centrality of idiosyncratic practices problematises the conditions under which $a$ work appears to exist by highlighting an intrinsic link with those who cultivate it. If a work comprises subjective practice as a fundamental feature, as opposed to a set movement structure, concept or so on, it arguably cannot be seen to exist beyond its makers, or be performed by anyone else. In response to this suggestion, I consider whether performative practices can be considered 'resistant', to borrow Pouillaude's use of the term (in Cvejić 2015, 10) to refer to works as resisting change and therefore persistent through time. To explore this topic, I will focus on Hay's work, and in particular on her use of scores. Unlike notated scores, they reproduce aspects of her practice, as opposed to structures of movement, thus reaffirming the claim that practice can be understood as an essential ontological feature of some works, and at times cannot be isolated from the artobject. Yet this enmeshed ontology does not necessarily mean that a work cannot outlive its creator: scoring allows for resistance, albeit in a very different way to codified notational systems.

\section{Dance work(s): Practice and Pragmatism}

Following the 'pragmatist' approaches outlined previously, it seems pertinent to consider the way the term 'work' and the work-concept operate within the dance world. As Cvejić points out, historically dance was subservient to and theoretically entangled within other art-forms, such as theatre $(2015,8)$. Furthermore, the way that dance performances exist physically only in the moment of instantiation, and the lack of universal notation system for dance, means that a work is less easy to pin down than in the case of musical and theatrical works, which often correspond to scores and texts. There have been multiple attempts to develop universal movement notations systems, dating back to 1700 (Hutchinson 1972, 2). During the twentieth century in particular multiple systems were developed, such as Benesh, Laban and Eshkol-Wachman notations. There are many possible motivations for the drive to develop notation, including the idea that comprehensive documentation of movement would allow dance works to 'survive its short lifespan' (Van Imschoot [2005] 2010). Furthermore, Pouillaude (2009) suggests that the development of notation systems allowed for dance works to circulate as autonomous objects. The 'work' could be considered an 'ideal' object, instantiated through performances that corresponding correctly to the notated score, therefore facilitating circulation beyond oral or bodily transmission (Pouillaude 2009, 216).

However, the use of codified notations is not widespread in dance practice. Furthermore, the drive to conceptualise dance works as 'ideal' objects has not been adopted by all. In conjunction with poststructuralist scholarship, the notion of the work has been disputed by some dance theorists, who adopted the concept of the 'text' as a way to challenge the stability associated with the term 'work', pointing to the potential for multiplicity and highlighting the role of the viewer in the construction of meaning (Adshead-Lansdale 1999, 2009). However, the notion of the dance text is 
a theoretical construct. It is uncommon for artists or audiences to use the term to refer to a particular production or dance object.

The term 'work' is not universally used either. Dance philosopher Anna Pakes (2015) points out that French choreographer Jérôme Bel's website lists 'performances', rather than works (www.jeromebel.fr). Further research of artists' websites reveals that Belgian choreographer Anne Teresa De Keersmaeker's company Rosas's site lists 'productions' (www.rosas.be), as does the site for UK-based Israeli choreographer Hofesh Shechter (www.hofesh.co.uk). Hay's website lists her 'dances' (dhdcblog.blogspot.com). Each of these options embodies an implicit resistance to the notion of the 'work'. However, despite not being universally adopted, the term is relatively frequently used by artists, companies and audiences, as well as scholars. For instance, the Rambert Dance Company website lists 'past works' and 'current works' (www.rambert.org.uk), and UK dance critic Judith Mackrell frequently refers to the 'work' under review (see Mackrell 2016a, 2016b).

The terminology adopted by artists is interesting and might reveal their political and/or artistic paradigm, as well as something about how they conceptualise what they do. However, ontologically speaking, the same type of thing can be referred to using different terms; therefore, the work-concept can be seen as distinct from the term, suggesting that whether or not practitioners use the word 'work', they may well produce entities that can arguably be considered under the work-concept. For example, Shechter's 'productions' are not necessarily a different type of thing to the works in Rambert's repertoire, purely due to a different choice of word. To further explain this point, I again draw on Goehr (1992), who argues that the musical work-concept emerged and became regulative of musical practices in the late eighteenth century. However, she suggests that this does not mean that composers in previous centuries were not producing works $(1992,113)$. She discusses how different terms might have indicated the work-concept prior to its emergence as a regulative notion (1992, 115-7).

But what makes something a work? Louppe ([1997] 2010) suggests that there are several 'givens' in relation to contemporary choreographic works. Firstly, a work is an original creation worthy of being 'signed' by an author. Secondly, she suggests that contemporary choreographic works belong equally to contemporary art and the field of dance. Thirdly, Louppe suggests that works must be polymorphous; emphasising the drive for originality in contemporary dance. She argues that works comprise original intentions and their own codes, contents and modes of actualisation $(2010,203)$, thus emphasising her focus on the field 'contemporary dance', rather than classical forms, such as ballet, for example, which has relatively set codes and modes of actualisation. In accordance with some elements of Louppe's view, dance practitioner and scholar Sarah Rubidge $(2000,206)$ suggests certain characteristics of works. Firstly, she proposes that works are produced by an author and made to be attended to by a spectator, listener or reader. Secondly, she argues that they must endure in an identifiable way. Lastly, Rubidge suggests that works must exhibit consistent structural and/or physical features, which allow for recognition.

These observations appear to arise from scrutiny of dance world practices. As acknowledged by Louppe, the field of contemporary dance is broad, comprising a wide range of vastly different 
forms, aesthetics, approaches and styles, and this diversity has only proliferated further in the time since Louppe's writing. Dances are performed in a range of contexts, including theatres, studios and public spaces. They are transmitted live, via recordings and more recently, over the internet. However, despite this multiplicity there does seem to be a commonality in terms of the way that dances are conceptualised. For example, we might refer to Israeli choreographer Itzik Galili's work A Linha Curva (2005) in general terms, discuss its features, debate its relevance, and so on, or we might talk in more specific terms about the experience of a certain performance, rating its merits over another, for example. ${ }^{7}$ This duality can be applied to dance entities of differing styles and forms, thus leading to the suggestion that works are distinct from their performances, which can be explained in multiple ways, including through the type-token schema. Furthermore, the way in which works seem to persist outside of performance means that the concept continues to be of use in dance world practice and discourse, to refer to an abstract entity, which is manifest in various events.

However, the term 'work' is also used to refer to what happens in the studio. At first glance this doesn't appear to be necessarily particularly complex or interesting. In common discourse we are able to distinguish between the verb and noun forms of the term. Upon closer inspection, however, these distinctions are not always clear. When I present a conference paper articulating the results of fieldwork for example, I present my 'work' to the audience. The work is articulated as an outcome of activity, rather than a demonstration of the action taken to get there. If I include a recording of the process of gathering data, I would be showing myself 'at work' or 'working', yet, in the moment of the conference presentation I am also 'at work' and 'working'. Presenting my work is also part of the work. The same muddling of labour and outcome occurs in dance practice, as performing the work entails both going to work and working.

Work is something we do, and a place where we go to perform duties. Those who go to work to make or perform a dance work are usually 'employed' to do so by another person or institution (hopefully, although not always, with a financial return). What is perhaps more interesting in relation to this enquiry is the way that the term 'work' is used not only to refer to these types of situations, but also by practitioners to refer to their practice, which often occurs both within and outside of employment contexts. Again, at first blush this does not appear to be particularly surprising: if dance-making entails practice, it is of course part of what dance-makers and performers do when 'working'. However, the term 'practice' in dance is often used not as a description of the process of working towards finishing a product, but rather describes searching for refinement, or operating in a state of exploration.

Practices take many forms; some people regularly work with codified methods such as yoga or Skinner Releasing Technique, whilst others develop idiosyncratic ways of developing and attending to movement. Repetition is key, as practices often become an integral part of training and making. Human geographer Nigel Thrift describes artists' practices as 'material bodies of work or styles that have gained enough stability over time, through, for example, the establishment of corporeal routines and specialised devices, to reproduce themselves' $(2008,8)$. Indeed, an artist's practice is often stabilised through repetition and perhaps shared though performance, teaching, discussion 
and writing. ${ }^{8}$ However, the key point here is that an artist's 'practice' is different from 'practising' in the sense associated with rehearsal. Whilst rehearsal might involve practice, not all practice is a rehearsal. This means that when an artist is engaged in her or his practice, she or he is at work, without necessarily constructing an object that can be performed, bought or sold. There is also a distinction to be made between process and practice. Although practice is processural, in the sense that working involves a constant state of becoming, there is a difference to be marked between a choreographic process, which implies a course of action directed towards the construction of a choreographic entity, and an artistic practice, which might be concerned with refinement, exploration or training and which tends to be undertaken for its own sake rather than directed towards a performance, work or object.

Giorgio Agamben $(1999,68)$ discusses how ancient Greek philosophers 'made a clear distinction between poiesis (poiten, "to pro-duce" in the sense of bringing into being) and praxis (prattein, "to do" in the sense of acting)', and suggests that the third category of 'work' was something purely necessary for existence, and seen as the bottom of the hierarchy. However, he goes on to argue, 'In the Western cultural tradition, the distinction between these three kinds of human doing poiesis, praxis, and work - has been progressively obscured' (69). Parallel to this convergence, work, which used to occupy 'the lowest rank in the hierarchy of active life', climbed to become of central value (70). These articulations help us to make sense of the way that artists refer to their practice as 'work', as the categories have become enmeshed; furthermore, when applied to activity the term 'work' can be understood as denoting value, whether or not it leads to economic return.

Both process and practice are increasingly shared in different contexts, a phenomenon which can be attributed to various economic, social and political factors. The foregrounding of dance-making as an activity rich in value is particularly prevalent in current contemporary dance in Europe and the USA. There appears to be an increased interest in articulating and disseminating components of choreographic and movement activity. ${ }^{9}$ Furthermore, the labelling of practice as 'work' can be seen as politically motivated, as it foregrounds the labour intensive nature of dance and demands that we see value in the practice itself, rather than in accordance with economically driven models of production. The development of Practice as Research ( $\mathrm{PaR}$ ) inevitably contributes to this shift in thinking. In UK institutions, academic qualifications are increasingly offered on the evaluation of practical research, as opposed to solely through written theorising. Although not exclusive to dance, this framework has had a significant impact on dance studies and making, as practice is foregrounded as a valuable, research-full and knowledge-rich activity. PaR might lead to the construction of a work to be shared through performance, or at times the research or process of making might be viewed as the primary outcome, therefore shifting the emphasis from 'product' to process.

$\mathrm{PaR}$ within universities is the result of a set of economic and cultural structures. It allows artists to develop their practice within relatively stable employment, as opposed to the more 'precarious' world of freelance performance-making. ${ }^{10}$ Furthermore, the integration of artists within teaching faculties might draw students to certain courses, thus providing economic gain for the university. Despite the economic structures surrounding PaR, I suggest that the foregrounding of process 
within the academy impacts upon artistic communities outside of academic institutions, and this concern with sharing practice often can be linked to a resistance to capitalist modes of production. On the one hand, drawing attention to the labour of making as the site of value shifts the emphasis away from a stable entity that can be bought and sold through performance events. For example, this area was explored at a residency organised by Independent Dance and Siobhan Davies Dance in 2014, in which twenty dance artists gathered together for four days to work together without focusing on producing a specific outcome. ${ }^{11}$ In a booklet collectively authored by the participants after the residency, some of the questions that are posed include: how can the arts 'still constitute a critical moment that is not subsumed under the pressures of the market?' and 'how can we shift the focus to process rather than product?' (Independent Dance 2014). On the other hand, however, is important to note the complexities of the claim that this approach undercuts contemporary capitalism. For instance, although not discussing this specific event, Bojana Kunst (2015) argues that such instances in fact demonstrate how artists' working patterns align them closely with current capitalism, which calls for creativity and flexibility on the behalf of the worker, and erodes the distinction between life and work.

\section{Coe and Morrissey: Performing Practice}

So, choreographic processes and practices are often shared, which can be read as an explicit or implicit political statement, but from an ontological perspective, what happens when process and practice are shared with an audience? The presentation of the labour of dance-making in performance can be traced back to the work of Judson Dance Theatre and seminal works such as Yvonne Rainer's Room Service (1963), a pedestrian work described by Sally Banes and Noël Carroll as involving, amongst other activities, 'two dancers carrying a mattress up an aisle in the theatre, out one exit and back in through another' $(1982,37)$. More recent examples include lecture demonstrations, such as those from Jonathan Burrows and Matteo Fargion (such as Rebelling Against Limit [2013]), for example, and work that involves conversation between the performers and spectators, such as Siobhan Davies' Table of Contents (2014). Each of these examples foreground the processes of the choreographer(s) and dancers in the construction and presentation of the work. However, the works are stable, repeatable entities, and the process of making is distinct from the process of performing. Thus, the internal and external aspects of the work, as articulated by Cvejić, can be seen as distinct.

In contrast to the performance of process is the performance of practice, which, as I will argue, is evidenced in the work of Coe and Morrissey. The duo have a shared movement practice that they have been developing since 2012 and that involves moving together in spontaneous action, in and out of contact. Whilst this might sound like improvisation, both artists state a resistance to this way of describing the work (Coe and Morrissey 2013). They are equally resistant to the term 'choreography', perhaps due to its association with planning and organisation. Instead, their focus is on their internal somatic states, as well as the cultivation of a sensed exchange between them. 
There is a joint recognition of a 'thing' that occurs among and for them both. Much of the practice involves trying to experience and in some cases, share this 'thing'. Coe and Morrissey structure their practice in 'rounds' (Coe and Morrissey 2013), moving together for around twenty or thirty minutes at a time, often completing multiple rounds in any session. Thrift's notion of corporeal routines relates to Coe and Morrissey's approach and their drive to find stability, but not fixation, through the repeated exploration of the 'thing'. To return to the

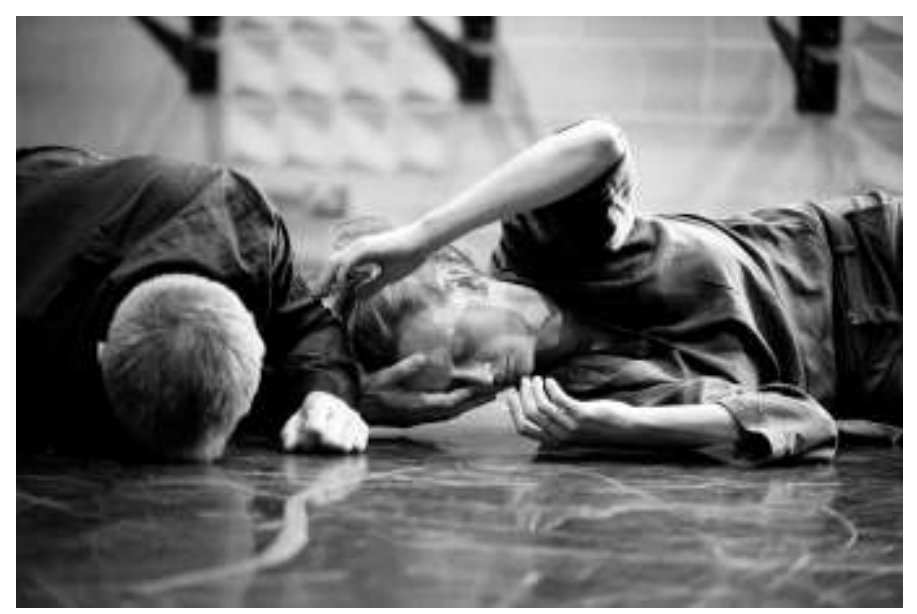

Image 1: Coe and Morrissey at work. Credit: Camilla Greenwell 2015. distinctions made in the preceding section, such activity can be understood as constituting 'practice', in that it involves exploration and an on-going enquiry into particular facets of movement.

Coe and Morrissey's practice presents itself as an ontologically complex entity. I have witnessed them at work multiple times over a two-year period, in both studio and stage contexts, with varied numbers of other people present. Whilst the company of others undoubtedly impacts on the action, they attempt not to disrupt their somatic states. In other words, the enmeshed experience and attention of their bodies and minds is the fundamental feature of the practice, and must be maintained for the work to be happening. Ideally for them, the only marker of difference between the private practice and public performance is the presence of an audience. Coe talks of trying to stay 'true' to the practice, which they both refer to as their 'work' (Coe and Morrissey 2015b). The practice is fundamentally focused on their experiences of moving. Insomuch as key features of the work are internal rather than public, we can perhaps see this aspect of the work as 'self-absorbed', to borrow Cvejić's terminology. Crucially, however, this 'thing' is also an essentially public entity, as their practice was developed to be shared with an audience (Coe and Morrissey 2015b). It was presented in multiple contexts between 2012-2015 and is continuing at the time of this writing, with each outing presenting a related but unique set of problematics about what it means to share practice. They also address the complications of watching an event where the focus is internal and remains on the experience of the performers, as opposed to constructing an object that 'faces' the audience in both concept and delivery.

The presentation and repetition of their practice seems to recall Cvejićs articulation of the duality of the 'sharable (exterior or public) and the reticent, self-absorbed or shattered aspects of a dance work' $(2015,10)$; in this case there appears to be little or no distinction between the two. This raises the question of what is meant by Cvejić in her use of the terms 'sharable', 'exterior' and 'public'. These words might refer to something being presented to an audience, or that which is accessible to others, as opposed to entirely internalised. It seems that she is referring to the distinction between the public performance and the reticent, internal process of making. However, there is a 
further distinction highlighted by Coe and Morrissey's work between those aspects of practice that are sharable with others and those that are entirely internal.

Sharing process within the studio is a relatively common form of engagement with dance; guests might be invited to see a work-in-process, sharing or rehearsal. Each of these instances differs in terms of its relationship to the notion of a finished work, and pose the question: is this practice, process or performance? When observed in the studio, Coe and Morrissey's work is usually framed as a sharing as opposed to a performance. How does this translate to a public theatre? In April 2015 Coe and Morrissey performed in the theatre space of Lilian Baylis Studio at Sadler's Wells Theatre in London, marking a significant moment of transition from the studio to the stage. For this event Coe and Morrissey invited philosopher Alva Noë and sound artist Graeme Miller to engage with the set of problems created by their wish to share their practice. The inclusion of other people, sound and text generated specific frames through which the practice was seen. Noë talked directly to the audience, commenting on the practice as it unfolded, and telling stories from his childhood. The visibility of Miller's sound equipment foregrounded the performative context. The movement became part of a larger event. Coe and Morrissey suggest that the presence of other people and choreographic components presented challenges to their desire to maintain a specific somatic state (Coe and Morrissey 2015b), causing distraction, intervention, and disruption and testing the limits of their ability to 'attend' (Coe and Morrissey 2013) to their practice. The decision to explore the practice within these conditions demonstrates their motivation to explore and probe the 'thing' they have cultivated by placing it within various different contexts. Indeed, although this was not the title of the Sadler's Wells event, Coe and Morrissey often refer to their practice as 'this thing that we do', a description suggested by Noë.

These interventions offered a more sculpted form to the work than when it was seen in a studio, something that had been constructed and rehearsed for a public, paying audience, within a conventional performance context. Whilst the studio practice seeks to share the internal aspects of the duo's process, these features combined offered a new mode of externality for the work and threatened to disrupt its status as a sharing of practice, as opposed to a finished work. So did this repositioning mean that the work of moving became $a$ work?

On the face of it there seems to be a shift from practice to performance, and the intentions of the event were different here from in the studio, due to the public, collaborative and performative context. However, while the context was different, the intentions and focus of the practice was unchanged, and Coe and Morrissey's activity remained the same. Let us return here to Louppe and Rubidge's articulations of the necessary conditions for a dance work, which can be summarised as being authored, sharable, identifiable, contextualised and enduring. Assuming that we are in agreement about these criteria, can Coe and Morrissey's offering be seen as a 'work'? It does appear to be authored, sharable, identifiable, contextualised and repeatable. However, while these articulations propose a set of necessary conditions, they are not sufficient, insomuch as there can be entities other than dance works that possess all of these features. Crucially, Coe and Morrissey do not see themselves as having constructed an artwork, and in fact they articulate resistance to the notion, whilst acknowledging that they have developed a public object (2015b). ${ }^{12}$ Perhaps each 
round is simply an individual event, distinct from the one that precedes and follows it. This would suggest that each instance of the practice is not linked to the others. However, this does not seem quite right. The practice is repeatable, and indeed it is enacted multiple times. Nevertheless, whilst it is possible for Coe and Morrissey to repeat it, the practice may or may not be enduring or 'resistant'.

It seems that there are two key features of Coe and Morrissey's work that mark it as ontologically distinct from conventional dance works. Firstly, the practice that happens in performance cannot easily be distinguished from that which occurs in the process leading up to it. Secondly, the ways in which this entity might be 'resistant' requires further consideration, due to the way that the practice is intrinsically linked to Coe and Morrissey. As quoted previously, Cvejić suggests that the resistance of dance works make them 'capable of surviving the death of its initial protagonists, or in other words, existing beyond the experience or memory of its creation and performance processes' $(2015,10)$. Can this work exist in this way?

It is hard to imagine that the work could be performed by anyone else, as it is dependent upon idiosyncratic and shared experiences, which appear difficult to articulate through language. Whilst it is possible that features of the practice might be communicated and enacted by others; whether or not such an occurrence would result in an instance of the very same thing remains open. This implies either that Coe and Morrissey have not constructed a work after all, or that we need to re-examine the claim that works are necessarily resistant beyond their creators. In either case, Coe and Morrissey's practice demonstrates the complexities of the workconcept. They consider their practice as 'the work' and aim to share this in performance contexts without making 'a work'. It is possible to argue that the work-concept applies to this example, despite the resistance to the notion, yet it does not smoothly align with the conditions described previously, due to the motivation to make internal and idiosyncratic experiences public, therefore problematising

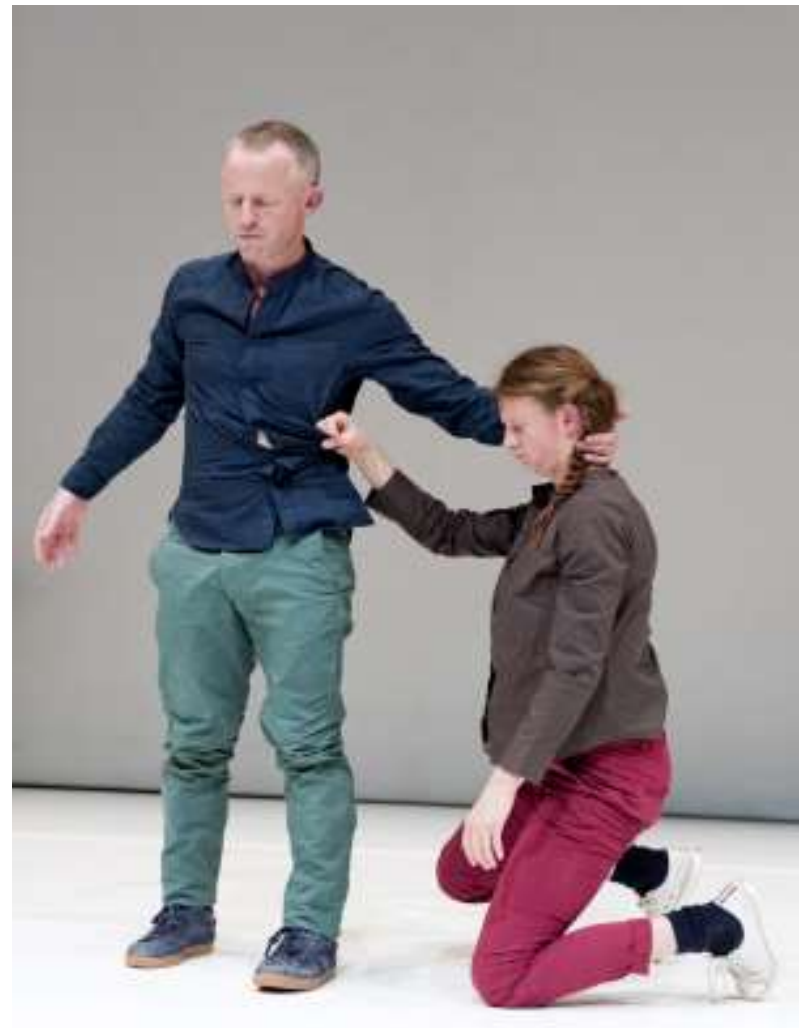

Image 2. Coe and Morrissey performing their practice. Credit: Christian Kipp 2015. the requirement that the work can circulate and persist beyond its creators. 
The questions that arise when practice is performed are similarly generated by Deborah Hay's work, however there is a key difference due to her use of scores for the transmission of her work. Like Coe and Morrissey, Hay has a detailed, idiosyncratic and introspective movement practice, yet she uses this practice to generate enduring choreographic works. Her practice is primarily concerned with listening to, and learning from her body, which she refers to as her teacher (2000, xxxiv). Movement arises from repeated questions and considerations such as, 'Where I am is what I need, cellularly' $(2000,6)$. Hay uses these provocations as the basis for exploring simple sequences of movement and challenging the habitual behaviour of the body. An interest in cells occurs repeatedly in Hay's writing, and she describes herself as interested in re-configuring her threedimensional body into a 'cellular' body (Hay 2013).

The presentation of practice is central to Hay's choreographic work. Of particular interest here is how the practice informs the development of her solo works. For example, No Time to Fly is a solo that Hay made for herself in 2010. It was developed as a public, sharable and external object, yet the focus of the work is not on cultivating specific forms for the viewer, but on sharing the movement practice. The appearance of Hay's work is hard to summarise. Referring to herself in the third-person, she says, 'It is difficult to describe her actions. It doesn't seem to be necessary' $(2000,23)$. The movement performed is unset; the work can, and should look different in every instantiation. Once Hay had developed the work, she wrote a score of it, which subsequently was used as the basis for a digital score of the work called Using the Sky (2013) developed as part of Motion Bank (http://scores.motionbank.org/dh/\#/set/sets). The written score articulates Hay's experiences in each moment of the dance. It is a tool for transmitting the work, but not through the articulation of movements. Instead, aspects of Hay's way of thinking and are stabilised through writing. For example, a section reads,

\footnotetext{
In response to the guidance received, I select the right moment to break the string and notice at once how the inclusion of the theater and my audience enlarges my dancing. It is like a real opening, and I begin again. (Hay 2013)
}

As demonstrated here, Hay's use of language is indeterminate and opaque, yet carefully meaningful. She refers to her practice as her 'work', yet also uses this term to refer to choreographic works. For example, in an interview entitled 'Practice as Performance' on Hay's Motion Bank site, she explains, 'And so my work and my choreographic work is insisting that the dancer that perform this work notice the potential for feedback from their whole body, and unless they're doing that the dance is not happening' (Hay 2013). This articulation provides an example of how the term is used to refer to both practice and performance making. This statement also highlights how Hay's practice is concerned with acknowledgment of the internalised aspects of practice, and yet this practice is placed in front of an audience, thus enmeshing the internal and external. Whilst this is arguably the case for any performance, the relationship between the performer, their body and the practice is central to Hay's work, meaning that the performance can 
be seen to make these relations public, thus echoing Coe and Morrissey's intention to share or make internal aspects of their practice available to viewers.

Despite the idiosyncrasy of Hay's practice, it is widely shared. The construction of spoken and written scores allows for the practice to 'resist' in Cvejić and Pouillaude's terms-that is, to exist beyond Hay's performance. This suggestion brings us to a recurring question in relation to dance of how or if dance can be transmitted through documentation. I do not wish to wade into the debate about the role and relevance of movement notations. However, the position and role of the 'score', broadly construed, does seem crucial for contemplating the potential for dance works to 'resist' their ephemerality.

In dance practice the term 'score' is used to refer to a wide array of physical and non-physical entities. Performance theorist Myriam Van Imschoot points out that unlike western classical music conventions, the 'score' in dance does not indicate a specific object, inscribed through standardised notation ([2005] 2010,11). Broadly speaking, scores provide parameters through which movement is instigated. Whilst some scores might follow the conventions of codified notational systems, others are inscribed through idiosyncratic writings, drawings and speech. Van Imschoot suggests that scores provide a way into praxis ([2005] 2010, 13), which is particularly significant in relation to Hay's scores, as she uses language to provide a set of indeterminate instructions, which the performer interprets in relation to their own bodies and experiences (D'Amato 2014).

These scores work in conjunction with other methods for articulating Hay's choreographic philosophy. For example, Hay's Solo Performance Commissioning Project, which ran from 19982012, involved dance artists commissioning one of Hay's solos and undertaking a week of intense coaching with her on the principles of her practice, before going on to develop their own adaptations of the work, with a commitment to at least three months of daily practice. This example demonstrates how working intensively with Hay's scores alone are not enough to instantiate the work; understanding of other elements of her practice is ontologically essential to any authentic adaptation of the work. As Van Imschoot writes, 'most scores in dance do not aspire to "autonomy" or "self-sufficiency"; they are heteronomous working tools, whose use is ad hoc, local and mostly in tandem with verbally or physically communicated agreements' ([2005] 2010, 11). However, they do provide a way for features of the work to transcend the performance event. The development of mechanisms to transmit elements of the work can be seen as driven by a desire to maintain the work.

Although they don't use a written notation, Coe and Morrissey also work with scores. Each round of their practice operates within an agreed set of parameters, usually concerning time, sight and their position in relation to one another at the start of the round. Despite the fact that these parameters function as scores, they are not frequently referred to as such. Furthermore, they are not inscribed or transmitted in a way that makes it possible for the principles of the practice to be enacted by anyone other than Coe and Morrissey. This reiterates the suggestions that their work may not be 'resistant', as it cannot be separated from them. Their practice does not appear to be transmittable as an entity divorced from their enactment of it. It is possible to argue that the same 
might have been true of Hay's solo works, except that she has chosen to develop devices through which the practice can be transmitted. Despite the fact that the scores discussed here are very different to codified movement notations, in my view these satisfy Pouillaude's suggestion (2009, 216) that the use of inscriptions allows for works to circulate, thus giving them the status of a 'work'. Developing devices through which the practice can be transmitted allows it to develop 'objecthood' and thus circulate as a commodity. Resisting this 'resistance' can perhaps be understood to further demonstrate a reluctance to 'produce' in the material sense and poses a challenge to the work-concept, as articulated by Louppe and Rubidge, by allowing for performance entities that cannot outlive their makers.

\section{Dance Work-Concept}

So where does that leave the dance work-concept? Goehr (1992) argues that the musical work is an 'open' concept, suggesting that such concepts have four key characteristics (91-92). I will address each of these in turn, in order to consider whether dance works can also be understood as such. Firstly, Goehr clarifies that open concepts do not correspond to fixed or static essences. This suggestion seems to align with dance works. As I hope this discussion has made clear, there does not appear to be a set of fixed essential properties that an entity must have in order to qualify as a work. Although Louppe and Rubidge provide observations about the characteristics of works, these are not an exhaustive set of criteria, and works may be accepted as such without embodying all of these standards. Secondly, Goehr suggests that open concepts do not admit of 'absolutely precise' definitions 'of the sort traditionally given in terms of necessary and sufficient conditions' (91). This issue was previously flagged in relation to Louppe and Rubidge's analyses, which do not provide such conditions. Indeed it is hard to imagine that such an outcome would be possible, especially given that one would first be required to find a working definition for dance. ${ }^{13}$

Goehr's third criteria for an open concept is that it is 'intentionally incomplete or "essentially contestable'" (91), thus acknowledging the potential for an unforeseen situation that would lead to the modification of existing definitions. Once again, this articulation seems to reflect practices around the dance work-concept, as demonstrated by Coe and Morrissey's presentation of practice, which does not smoothly align with existing understandings of dance works, as distinct from the processes of making. Lastly, Goehr suggests that open concepts are distinct from, but related to, vague concepts (91). She refers to Waismann's suggestion that a concept is vague when there are cases in which there is no definite answer as to whether or not the term applies. This discussion has demonstrated how this seems to be the case with dance works. Although we might refer to something as a 'work', there is no clear-cut definition, meaning that it is possible to argue that there are no definite answers. Furthermore, Coe and Morrissey's work highlights this lack of clear-cut definition, by existing somewhere on the edge of the work-concept. However, this example is relatively marginal, and there are multiple cases in which the work-concept seems to function in a non-vague way. Indeed, common practices seem to imply that we don't generally have much trouble distinguishing 'works' from related entities, such as dances occurring in social contexts, for example. 
Despite the multiple forms that dance works take, it seems as though we generally conceive of them as entities that exist in some way and can be instantiated, discussed and so forth. We might want to argue that they are essentially unset, or that the duality of work and performance is incorrect, but I suggest that the work-concept remains. Writing about the complexities of dance works, Armelagos and Sirridge suggest, "This notion of "the work" is useful and close to common sense; no one wants to lose it entirely' $(1978,132)$. Although I argue that the concept persists, this discussion has highlighted need for a conception of the concept that allows for vastly varied types of things, at times intrinsically linked to their making.

Although I have previously articulated some reservations about the applicability of type-token schema (see Blades 2011), the cases under discussion here do not directly challenge this way of thinking about the relationship between works and performances. Furthermore, there are different ways of thinking about types, and whilst the conditions of platonic types as eternal, unchanging entities might be too strict, ${ }^{14}$ there seems no immediate reason that an entity such as Coe and Morrissey's practice cannot be conceptualised as a type, with each round a token of it. Equally, this schema can be applied to Hay's work, and helps us to make sense of the ways in which there are multiple different versions of some of her works.

\section{Conclusion}

In reference to Pouillaude, Cvejić proposes that dance works are at once public and resistant and goes on to refer to the relationship between the public or sharable features of the work and its reticent, self-absorbed or shattered features $(2015,10)$. In the case of Coe and Morrissey and Hay, this relationship is fluid and flexible, to the point that the distinction between the 'self-absorbed' practice and the public-facing performance appears hard to locate. Furthermore, their work is in some ways motivated by a desire to make internal experiences 'public' and sharable. Hay's work demonstrates a confluence of practice and performance; however, as her work 'objects' are transmitted orally and via written scores, they are more conventional than those of Coe and Morrissey. This example goes some way towards illustrating Pouillaude's claim that notation (or in this case other forms of score) might be central to dance events becoming works. Whilst codified notation is not commonly used in contemporary dance practice, the transmission of work and works via written or verbal 'scores', or even the prescription of embodied forms of transmission, allows for practices and products to persist beyond their creators.

As Cvejic suggests, the relationship between the internal and external features of a work is idiosyncratic, but the cases considered here are not entirely unique. In that case, what relevance does this study have for dance practices more generally? Louppe suggests,

\footnotetext{
In the twentieth century the most visible transformation in the choreographic work has been in the multiplication of its modes of actualisation: changes in 'size' (format), displacement of its representational frames, quantitative and qualitative diversification of forms. (Louppe 2010, 204)
} 
I suggest that whilst choreographic processes have been foregrounded in performance for many years, the foregrounding of practice is perhaps less common and gives rise to another 'mode of actualisation'.

Whether or not it is intended as such, I would argue that the conflation of practice and product can be interpreted as a political statement. Foregrounding labour and internal experience explicitly contests the notion of the work as a stable, complete entity, distinct from its maker(s), which can be bought and sold, thus refocusing the site of value. Similarly, a resistance to persistence, as shown through Coe and Morrissey's reluctance to adopt the work-concept and circulate the practice through notation or written scores, can be seen as an opposition to certain forms of (re)production. Of course, it can be argued that to move, or even simply to be, is to produce, and in this way practice is a form of production. However, I suggest that non-production is an ideology that drives particular forms of practice and performance-making. The resistance to produce a resistant 'object' can be understood to respond implicitly or explicitly to the dance work-concept, as the cultivation of public entities in which the public and private are enmeshed challenges the idea of a stable, persistent work.

When the term 'work' is applied to practice, it does not necessarily indicate the dance workconcept per se, but being used as a verb, to describe the labour of practice. However, when this work-verb is placed in a performative context it occupies the place of an entity that could be considered as a work-noun, and therefore belong to the dance work-concept. This transition might happen despite opposition to the concept on behalf of the artist, as the concept and term are not necessarily one and the same. As with Goehr's account of musical works, I suggest that the dance work-concept is an open one. However, moving away from Goehr, I suggest that the concept refers not solely to stable art objects, but also indicates entities that are not constructed as 'works'. Importantly, it is possible to argue that every instance of dance involves the presentation of a certain practice. However, the framing, teaching and discussion of the two examples examined here demonstrates a drive to foreground practice.

This discussion has drawn on a range of perspectives, following the frameworks in analytic philosophy that centralise human practices in ontological methodologies, thus demonstrating a resistance to positivist logic through the foregrounding of human experience. Examining how the term 'work' is used to refer to practice, process and product suggests that practice can be considered under the work-concept, extending existing understandings of the concept in which it refers to stable, resistant entities, and demonstrating that it can also be an active and open concept. I maintain that the notion is a useful one, and that, if we allow for a troubling of its association with stable, tradeable objects, the concept helps us to explore and make sense of dance objects and practices. 
${ }^{1}$ Originally the term 'Continental' denoted philosophical work occurring on the European continent, and 'analytic' referred to Anglo-American scholarship, but that the distinction has come to be thought of as 'competing conceptions of the philosophical enterprise itself' (Cutrofello 2005: 1). However, it is possible to suggest that these distinctions may not be helpful or necessary.

2 Writing about 'dance', 'performance', and 'choreography' is not an easy endeavour, due to the philosophically loaded nature of each of these terms. Whilst the nuances and implications of each of these terms is not the main focus of this paper, it is important to acknowledge that the language I use is not without complexities.

3 For examples of the former, see Anderson (1983), Carr (1987), Margolis (1981), McFee (1992, 2011), Meskin (1999), Pakes (2013), Sparshott (1995) and Van Camp (1998). For the latter, see Cvejić (2015a), Pouillaude (2009) and Rubidge (2000).

${ }^{4}$ Pouillaude's text Le Désoeuvrement Chorégraphique: Etude Sur la Notion D'oeuvre En Danse (2009) is currently unavailable in English.

5I have observed Coe and Morrissey's collaborative practice multiple times over a two-year period, and I was involved in a performative sharing of the work at the Thinking Dance conference at Leeds University in October 2015.

${ }^{6}$ Van Camp (2006) points out that that there is a multitude of activities and ways of talking that occur within such worlds $(42,44)$. McFee (2011) uses the notion of 'The Republic of Dance' to conceptualise a similar notion (25).

7 See Pakes (2013) and McFee $(1992,2011)$ for detailed discussions of the distinction between works and performances.

8 Deborah Hay is an example of a dance artist who shares her practice in multiple performative and text-based outputs. See Lamb at the Altar: The Story of a Dance (1994); My Body, The Buddhist (2000).

9 This suggestion is made in response to an observed proliferation of 'audience development' activities, such as Q and A sessions and after-show discussions, alongside digital projects such as Motion Bank, which seeks to analyse and disseminate features of choreographic practices. See http://motionbank.org/.

10 See Kunst (2015) and Schneider and Ridout (2012) amongst others, for discussions of the precarious working conditions associated with performance making.

11 Coe was one of the people facilitating this event, and I was a participant.

12 Here I use the term 'public' to indicate Coe and Morrissey's intention to make accessible the internal aspects of the process and share the practice with others.

13 See McFee (1992) and Jones (1999), amongst others for discussions regarding the lack of definition for dance.

14 See McFee (2011) and Pakes (2013) for more detailed discussions regarding the applicability of platonic types to dance works. 


\section{Works Cited}

Adshead-Lansdale, Janet, ed. 2008. Decentring Dancing Texts: The Challenge of Interpreting Dances. New York: Palgrave Macmillan.

ed. Dancing Texts: Intertextuality in Interpretation. London: Dance Books.

Agamben, Giorgio. 1999. The Man Without Content. Translated by Georgia Albert. Stanford: Stanford University Press.

Anderson, Jack. 1983. "Idealists, Materialists, and the Thirty-Two Fouettés." In What is Dance?, edited by Roger Copeland and Marshall Cohen, 410-420. New York: Oxford University Press.

Armelagos, Adina and Mary Sirridge. 1978. "The Identity Crisis in Dance." The Journal of Aesthetics and Art Criticism 37 (2): 129-139. http://dx.doi.org/10.2307/429836

Banes, Sally and Noël Carroll. 1994. "Working and Dancing: A Response to Monroe Beardsley's What is going on in a Dance?"' In Writing Dancing in the Age of Postmodernism, edited by Sally Banes, 10-15. Middletown CT: Wesleyan University Press.

Blades, Hetty. 2011. "Dance on the Internet: An Ontological Investigation." Postgraduate Journal of Aesthetics, 8 (1): 40-52. http://www.pjaesthetics.org/index.php/pjaesthetics/article/viewFile/64/61

Burrows, Jonathan and Matteo Fargion. 2013. Rebelling Against Limit. Premiere Düsseldorf.

Carr, David. 1987. "Thought and Action in the Art of Dance." British Journal of Aesthetics 27 (4): 345-357. http://dx.doi.org/10.1093/bjaesthetics/27.4.345

Coe, Katye and Charlie Morrissey. 2015a. Wild Card - Katye Coe: Preparation. Presented at Sadler's Wells Theatre, London.

2015b. Interview with Hetty Blades. Siobhan Davies Studio, London.

2013. Personal conversations during studio observations. Coventry University UK.

Cull Ó Maoilearca L Laura. 2014. "Performance Philosophy - Staging A New Field." In Encounters in Performance Philosophy, edited by Laura Cull Ó Maoilearca and Alice Lagaay, 15-38. London: Palgrave Macmillan.

Cull Ó Maoilearca, Laura and Alice Lagaay. 2014. "Introduction." In Encounters in Performance Philosophy, edited by Laura Cull Ó Maoilearca and Alice Lagaay, 1-14. London: Palgrave Macmillan.

Cutrofello, Andrew. 2005. Continental Philosophy: A Contemporary Introduction. New York and London: Routledge.

Cvejić, Bojana. 2015. "From Odd Encounters to a Prospective Confluence: Dance Philosophy." Performance Philosophy 1:7-23. http://dx.doi.org/10.21476/PP.2015.1129

D’Amato, Alison. 2014. "Performing Interpretation: Writing for the Body in Three Indeterminate Language Scores." Paper presented at Writing Dancing/Dancing Writing, Joint Conference of SDHS and CORD, Iowa University, 13-16 November. https://sdhs.org/proceedings-2014

Davies, David. 2009. "The Primacy of Practice." The Journal of Aesthetics and Art Criticism 67 (2): 159-171. http://dx.doi.org/10.1111/j.1540-6245.2009.01345.x

___. 2004. Art as Performance. Oxford: Blackwell.

Davies, Siobhan. 2014. Table of Contents. Premiere ICA, London.

Galili, Itzik. 2005. A Linha Curva. Premiere Teatro Municipal de São Paolo.

Goehr, Lydia. 1992. The Imaginary Museum of Musical Works: An Essay in the Philosophy of Music. Oxford: Oxford University Press.

Hay, Deborah. 2013. "Using the Sky." Motion Bank. http://scores.motionbank.org/dh/\#set/sets 2010. No Time to Fly. Premiere St. Mark's Church in-the-Bowery, New York. 
___ 2000. My Body, The Buddhist. Middletown CT: Wesleyan University Press.

1994. Lamb at the Altar: The Story of a Dance. Durham NC: Duke University Press.

Hutchinson, Ann. 1972. Labanotation or Kinetography Laban: The System of Analyzing and Recording Movement. London: Oxford University Press.

Independent Dance. 2014. What Now [documentation booklet]. London: Independent Dance and Siobhan Davies Dance.

Jones, Sue. 1999. "Do Rabbits Dance? A Problem Concerning the Identification of Dance." In Dance, Education and Philosophy, edited by Graham McFee, 85-100. Oxford: Meyer and Meyer Sport.

Kunst, Bojana. 2015. Artist at Work: Proximity of Art and Capitalism. Alresford UK: Zero Books

Lepecki, André. 2006. Exhausting Dance. New York: Routledge.

Louppe, Laurence. (1997) 2010. Poetics of Contemporary Dance. Translated by Sally Gardner. Alton: Dance Books.

Mackrell, Judith. 2016a. "Rambert Review - Lucy Guerin's Zombie Dance Chanel Macbeth's Hurlyburly." The Guardian. May 11. https://www.theguardian.com/stage/2016/may/11/rambert-review-lucy-guerin-dancersmacbeth

___. 2016b. "LA Dance Project Review - Millepied Goes for Some Balanchine Shine." The Guardian. June 27. https://www.theguardian.com/stage/2016/jun/27/la-dance-project-review-benjamin-millepied-sadlerswells-london

Margolis, Joseph. 1981. "The Autographic Nature of the Dance." The Journal of Aesthetics and Art Criticism 39 (4): 419-427. http://dx.doi.org/10.2307/430241

Margolis, Joseph. 1959. "The Identity of a Work of Art." Mind (68) 269: 34-50. http://dx.doi.org/10.1093/mind/LXVIII.269.34

McFee, Graham. 2011. The Philosophical Aesthetics of Dance: Identity, Performance and Understanding. Hampshire: Dance Books.

1992. Understanding Dance. London: Routledge.

Meskin, Aaron. 1999. "Productions, Performances and Their Evaluation." In Dance, Education and Philosophy, edited by Graham McFee, 45-62. Oxford: Meyer and Meyer Sport.

Pakes, Anna. 2015. "Philosophy and the Work of Conceptual Dance." Paper presented at Dance Studies Colloquium, Temple University, Philadelphia, 17. http://ivestream.com/accounts/1927261/events/3377785/videos/80603405

2013. "The Plausibility of a Platonist Ontology of Dance." In Thinking Through Dance: The Philosophy of Dance Performance and Practices, edited by Jenny Bunker, Anna Pakes, and Bonnie Rowell, 84-101. Hampshire: Dance Books.

Peirce, Charles. 1906. "Prolegomena to an Apology for Pragmaticism." The Monist, 16: 492-546. Reprinted 1974 in vol. 4 of C. S. Peirce, Collected Papers, edited by Charles Hartshorne and Paul Weiss. Cambridge MA: Harvard University Press.

Pouillaude, Frédéric. 2009. "D’une Graphie Qui Ne Dit Rien", in Frédéric Pouillaude, Le Désoeuvrement Chorégraphique: Etude Sur la Notion D'oeuvre En Danse, 207-242. Paris: Vrin.

Rainer, Yvonne. 1963. Room Service. Premiere Judson Church, New York.

Rubidge, Sarah. 2000. "Identity and the Open Work." In Preservation Politics: Dance Revived, Reconstructed, Remade, edited by Stephanie Jordan, 205-215. London: Dance Books.

Ridout, Nicholas, and Rebecca Schneider. 2012. "Precarity and Performance: An Introduction." TDR/The Drama Review 56 (4): 5-9. http://dx.doi.org/10.1162/DRAM a 00210

Sparshott, Francis. 1995. A Measured Pace: Towards A Philosophical Understanding of the Arts of Dance. Toronto: University of Toronto Press. 
Thrift, Nigel. 2008. Non-Representational Theory: Space, Politics, Affect. Abingdon: Routledge.

Thomasson, Amie. 2006. "Debates about the Ontology of Art: What Are We Doing Here?" Philosophy Compass 1 (3): 245-255. http://dx.doi.org/10.1111/j.1747-9991.2006.00021.x

- - . 2005. "The Ontology of Art and Knowledge in Aesthetics." The Journal of Aesthetics and Art Criticism 63 (3): 221-229. http://dx.doi.org/10.1111/1.0021-8529.2005.00202.x

Van Camp, Julie. 2006. "A Pragmatic Approach to the Identity of Works of Art." Journal of Speculative Philosophy 20 (1): 42-55. http://dx.doi.org/10.1353/jsp.2006.0017

_-_. 1998. "Ontology of Dance." In Oxford Encyclopaedia of Aesthetics, edited by Michael Kelly. Oxford: Oxford University Press.

Van Imschoot, Myriam. (2005) 2010. "Rest in Pieces: On Scores, Notation and the Trace in Dance." Multitudes 21: 1-8. http://www.make-up-productions.net/media/materials/RestsInPieces Myriam\%20VanImschoot.pdf

Wollheim, Richard. 1975. Art and its Objects. Harmondsworth: Penguin.

\section{Biography}

Dr Hetty Blades is a Postdoctoral Research Assistant in the Centre for Dance Research (C-DaRE) at Coventry University, where she completed her PhD in 2015. She has published papers and chapters on the ontology of dance in relation to technology, addressing philosophical questions around ontology, identity, and analysis. She is an Editorial Assistant for the Journal of Dance and Somatic Practices.

(c) 2016 Hetty Blades 